\title{
SÍNTESE DO PERCLORETO DE FERRO A PARTIR DAS ÁGUAS RESIDUAIS DA PRODUÇÃO DE BIODIESEL TRATADAS POR ELETROFLOCULAÇÃO PARA CONFECÇÃO DE PLACAS DE CIRCUITO IMPRESSO
}

\author{
S. P. VIEIRA, F. C. F. OLIVEIRA E L.A.P. CAVALCANTI* \\ Instituto Federal de Educação, Ciência e Tecnologia da Bahia \\ luiz.cavalcanti@ifba.edu.br*
}

Submetido 26/09/2016 -Aceito 06/02/2017

DOI: $10.15628 /$ holos.2017.5160

\section{RESUMO}

A produção de biodiesel por rota metílica por catálise alcalina, geralmente, exige uma etapa de purificação gerando águas residuais que na sua composição apresentam componentes contaminantes inviabilizando o seu descarte, como estabelece a Resolução CONAMA $n^{\circ}$ 430/2011. Alternativas de reuso e aplicações práticas visando a minimizar a contaminação hídrica tem sido alvo de diversos estudos da comunidade científica. 0 processo de eletrofloculação foi usado para o tratamento das águas residuais da etapa de purificação do biodiesel. O tratamento foi realizado em reator eletroquímico constituído de eletrodos retangulares de ferro com $9 \mathrm{~cm}$ de comprimento e $3 \mathrm{~cm}$ de largura. Os eletrodos foram fixados em um béquer de $0,5 \mathrm{~L}$, através
\end{abstract}

de uma estrutura metálica, e a eles foram soldados fios que se ligam à fonte geradora de corrente contínua de intensidade 2,0 A, alimentado por um sistema fotovoltaico. O efluente resultante composto, principalmente, por cloreto de ferro II foi oxidado pela adição de peróxido de hidrogênio a cloreto de ferro III (percloreto de ferro). A solução sobrenadante foi separada para testes de coagulação e a solução residual teve seu $\mathrm{pH}$ diminuído até o valor 1,0 . Posteriormente, a solução foi concentrada em estufa por $6 \mathrm{~h}$ a $90^{\circ} \mathrm{C}$. A solução de percloreto obtida a partir das águas residuais da produção de biodiesel foi empregada para confecção de placas de circuito impresso.

PALAVRAS-CHAVE: Percloreto de ferro, Água residual, Eletrofloculação, Placas de circuito impresso.

\section{IRON PERCHLORATE SYNTHESIS FROM WASTEWATER OF BIODIESEL PRODUCTION HANDLED BY ELETROFLOCULATION FOR PRINTED CIRCUIT BOARDS MANUFACTURE}

\begin{abstract}
The production of biodiesel by methyl route with alkaline catalysis usually requires a purification step which generates waste water with contaminants components in its composition becoming unavailable for disposal as established by the CONAMA Resolution No. 430/2011. Reuse alternatives and practical applications in order to minimize water contamination has been the subject of several studies of the scientific community. Electrofloculation process was used for the treatment of wastewater from biodiesel purification step. The treatment was carried out at a electrochemical reactor consisting of iron rectangular electrodes with $9 \mathrm{~cm}$ long and $3 \mathrm{~cm}$ wide. The electrodes were placed in a $0.5 \mathrm{~L}$
\end{abstract}

beaker, through a metal structure, and wires were soldered at its structure and connected to an electrical source with 2.0 A intensity DC supplied from a photovoltaic system. The resulting effluent mainly composed of iron II chloride was oxidized by adding hydrogen peroxide to iron III chloride (iron perchlorate). The supernatant solution was separated for coagulation tests and the residual solution had the $\mathrm{pH}$ value decreases to 1.0. Subsequently the solution was concentrated in an oven for $6 \mathrm{~h}$ at $90^{\circ} \mathrm{C}$. The perchlorate solution obtained from the waste water from biodiesel production was used for making printed circuit boards.

KEYWORDS: Iron perchlorate, Residual water, Eletrofloculação, Printed circuit boards. 


\section{INTRODUÇÃO}

A crescente preocupação com as alterações climáticas, escassez de água e diminuição das reservas mundiais de petróleo tem contribuído para diversos estudos da comunidade científica mundial. Os biocombustíveis apresentam baixa toxicidade, são biodegradáveis, renováveis e capazes de reduzir substancialmente a emissão de gases de efeito estufa. Tais características fazem que os combustíveis derivados da biomassa sejam considerados como potenciais substitutos daqueles de origem fóssil (DOGAN \& TEMUR, 2013, p. 793). O biodiesel surge como alternativa ao diesel do petróleo, definido como combustível composto por alquil ésteres de ácidos graxos de cadeia longa, derivado de óleos vegetais, gorduras animais, óleos residuais ou algas (MOSER, 2014, p. 500).

O biodiesel consumido no Brasil, geralmente, é obtido por transesterificação alcalina homogênea, na qual se recorre à etapa de purificação com separação da glicerina formada como subproduto, seguida de lavagem com solução ácida, para retirada de resíduos de óleo não reagido, do catalisador e álcool e finalmente algumas lavagens com água para a retirada de resquícios de resíduos, ainda, presentes no biodiesel. Essa água pós-lavagem contém uma quantidade elevada desses resíduos, portanto, deve ser tratada antes do reuso ou descarte (ELICKER et al., 2015, p.2498). O processo de purificação do biodiesel convencional com água, apesar de apresentar significativa eficiência, gera um grande volume de efluente líquido, geralmente são consumidos em média três litros de água para cada litro de biodiesel produzido, que devido às impurezas presentes não pode ser descartado diretamente nos cursos d'água, conforme estabelecido pela Resolução CONAMA no 430/2011 (FLECK, 2011, p.12).

Dentre os diversos processos para tratamento das águas residuais da purificação do biodiesel a eletrofloculação ocupa uma posição de destaque. O processo utiliza a eletrólise para separação das impurezas e a água. A redução das variáveis físicas e químicas do efluente (DBO, DQO, óleos e graxas, turbidez e cor aparente) é garantida pela aplicação desse método simples e eficiente de separação (VIEIRA et al., 2015, p.146). O processo de eletrofloculação é economicamente inviável quando se utiliza a energia elétrica convencional para fornecimento de corrente para o sistema. Estudos realizados por Nascimento et al. $(2015$, p.43) apontam que o processo de eletrofloculação para o tratamento das águas residuais de biodiesel, torna-se economicamente viável quando se utiliza um sistema fotovoltaico para fornecimento de corrente elétrica ao reator eletroquímico.

Cordeiro et al. (2015, p. 56) avaliaram o efeito da eletrofloculação para o tratamento das águas residuais da produção de biodiesel com resultados significativamente satisfatórios, com redução na turbidez $(99,96 \%)$, cor aparente $(81,66 \%)$, DQO $(65,19 \%)$, DBO5 $(60,37 \%)$ e óleos e graxas $(30,88 \%)$, para um tempo de exposição ao tratamento de 10 min e diferença de potencial de 7,5 V. Os mesmos autores sugerem, ainda, que a água tratada seja reutilizada no processo de purificação do biodiesel. Tal alternativa é inviável, uma vez que no efluente tratado ainda há um teor de ferro ou alumínio (a depender do eletrodo utilizado) residual alto. A presença de tais 
metais acelera as reações de autoxidação do biodiesel (KNOTHE et al., 2006, p.134; JUNQUEIRA et al., 2015, p4).

O simples descarte do efluente resultante do processo de tratamento da água residual da produção do biodiesel via eletrofloculação não é indicado, apesar dos parâmetros físico-químicos se enquadrem dentro limites previstos na Resolução CONAMA no 430/2011 (BRASIL, 2011, p.4), o teor de ferro ou alumínio é alto, podendo causar contaminação dos ambientes aquáticos. Sendo assim, alternativas para reutilização do efluente gerado no processo de eletrofloculação devem ser avaliadas visando minimizar as consequências do seu descarte nos cursos hídricos. Vieira et al. (2015) avaliaram o tratamento das águas residuais da produção de biodiesel via eletrofloculação com eletrodos obtidos a partir do reuso de latinhas de alumínio, obtendo resultados expressivos com redução na turbidez (97\%), DQO (85\%) DBO5 (87\%), óleos e graxas (84\%). Os autores sintetizaram o alúmen de potássio a partir do efluente gerado no processo.

Na fabricação de placas de circuito impresso, na área de eletrônica, é comum a utilização de percloreto de ferro (cloreto férrico) como agente corrosivo. Protege-se parte da placa geralmente com tinta e as trilhas do circuito serão atacadas pelo agente corrosivo. Quando o biodiesel for produzido por catalise homogênea como metóxido de potássio sua água residual após lavagem ácida, com ácido clorídrico $(\mathrm{HCl})$, terá como produto de reação de neutralização ácido-base o sal cloreto de potássio $(\mathrm{KCl})$. O sal disperso no efluente será possível a produção do percloreto de ferro que poderá ser aplicado na confecção de placas de circuito impresso.

O presente trabalho tem por objetivo tratar a água residual da produção do biodiesel por rota metílica via eletrofloculação e a partir do efluente gerado desse processo sintetizar o percloreto de ferro para utilização como agente corrosivo de placas de circuito impresso.

\section{METODOLOGIA}

\subsection{Materiais}

A célula eletrolítica para o processo foi montada em recipiente de vidro, empregando como eletrodos de ferro, cortados e lixados para retirar a tinta, com dimensões de $9 \mathrm{~cm}$ de comprimento e $3 \mathrm{~cm}$ de largura. Uma fonte alimentadora (marca Instrutherm, modelo FA 3030) foi usada para a geração da corrente contínua no processo, ligada a um sistema fotovoltaico. Os compostos químicos como metanol, hidróxido de potássio e ácido clorídrico com $99 \%$ de pureza foram adquiridos junto à VETEC, Sigma-Aldrich Brasil (NASCIMENTO et al., 2015, p.45).

\subsection{Produção de biodiesel}

O biodiesel metílico de soja (B100-S) foi produzido através da reação de transesterificação alcalina em presença de $\mathrm{KOH}$, com razão molar óleo:metanol de 1:6. O processamento foi desenvolvido em reator de vidro (Marconi, modelo MA502/5/C, volume útil $1 \mathrm{~L}$ ) com controle de temperatura e agitação mecânica (impelidor do tipo pás), nas condições operacionais: $50{ }^{\circ} \mathrm{C}, 1$ atm, $300 \mathrm{rpm}$ e tempo reacional de $1 \mathrm{~h}$. Em seguida, procedeu-se a separação da glicerina da 
mistura reacional via decantação. A fase mais leve da mistura contendo o B100-S, o catalisador e o excesso de metanol, passou pela etapa de purificação que constou de evaporação do metanol com auxílio de um evaporador rotativo (IKA, modelo RV10) com condensador vertical, seguida de uma lavagem ácida com solução de ácido clorídrico 0,5 M. A água de lavagem ácida foram adicionados $2 \mathrm{~g}$ de cloreto de potássio $(\mathrm{KCl})$ para aumentar a condutividade do efluente. Lavagens posteriores foram realizadas com água destilada. As águas residuais resultantes do processo de purificação foram colhidas em recipientes adequados e submetidas ao tratamento de eletrofloculação (CAVALCANTI, 2013, p.57).

\subsection{Dispositivo de eletrofloculação}

O tratamento da água de lavagem nesse processo foi realizado em reator eletroquímico operado em batelada (béquer de plástico, volume útil 0,5 L) constituído de dois eletrodos de ferro, com $9 \mathrm{~cm}$ de comprimento e $3 \mathrm{~cm}$ de largura. Os eletrodos foram fixados no reator, nesses foram fixados fios de cobre ligados à fonte de corrente contínua $(2,0 \mathrm{~A})$ alimentada por um sistema fotovoltaico, conforme o esquema apresentado na Figura 1 . Foi adicionado ao reator $0,2 \mathrm{~L}$ da solução a ser tratada, proveniente da água de lavagem obtida na produção do biodiesel. $\mathrm{Na}$ sequência, o sistema foi operado durante $10 \mathrm{~min}$ sendo o efluente resultante utilizado para produção do percloreto de ferro.

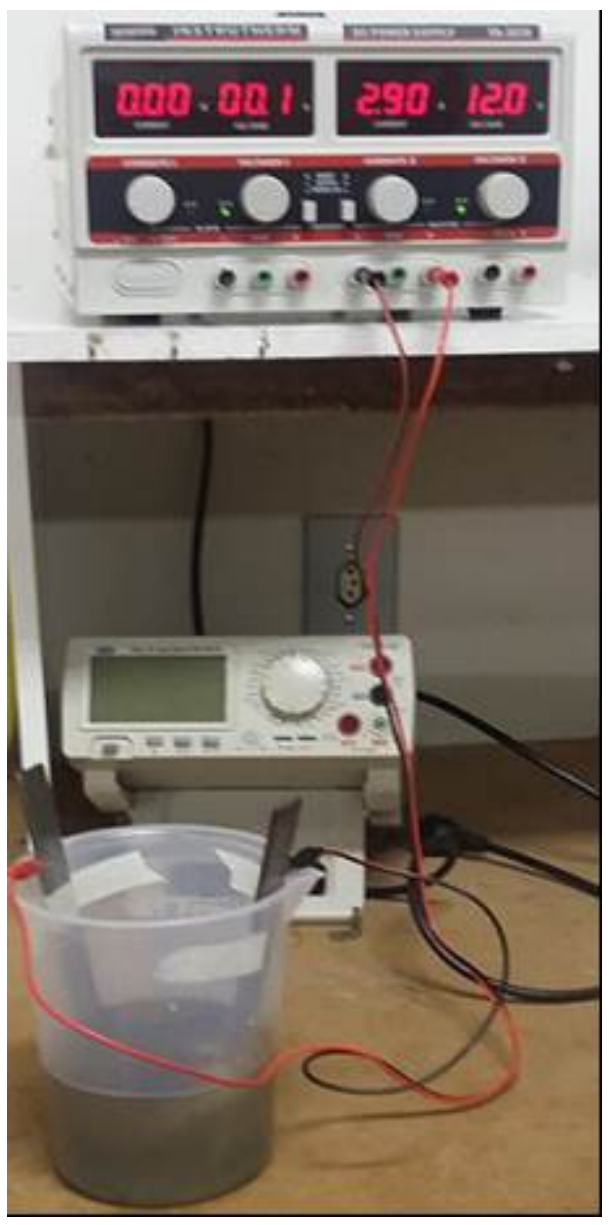

Figura 1: Montagem do reator eletroquímico para eletrofloculação da água de lavagem do biodiesel. 


\subsection{Produção do percloreto de ferro}

Ao efluente resultante do processo de eletrofloculação foram adicionados $0,03 \mathrm{~L}$ de peróxido de hidrogênio a $35 \%(\mathrm{v} / \mathrm{v})$. Na etapa seguinte, o pH da solução foi diminuído para $1,0 \mathrm{e}$ deixado em inércia por $5 \mathrm{~h}$. A solução sobrenadante foi retirada com o auxílio de uma pipeta graduada, enquanto a solução residual foi levada a estufa a $90^{\circ} \mathrm{C}$ por $6 \mathrm{~h}$.

\subsection{Confecção da placa de circuito impresso (PCI)}

Partindo de uma placa de circuito impresso virgem tipo fenolite, recortou-se a referida placa em dimensões adequadas ao circuito a ser inserido. Removeram-se as oxidações da superfície da placa com o auxílio de uma lixa. Na sequência, aplicou-se uma camada de tinta com o auxílio de caneta permanente (geralmente utilizada em CDs, DVDs). O desenho das trilhas na placa foi realizado manualmente, retirando-se a camada de tinta, onde se desejava que o percloreto de ferro atuasse como agente corrosivo. Posteriormente, a placa foi imersa na solução de percloreto de ferro sob agitação por $5 \mathrm{~min}$. Na última etapa, removeu-se a tinta, e a placa foi perfurada nos locais destinados aos componentes eletrônicos, onde estes foram inseridos e soldados (SILVEIRA et al., 2013, p.4).

\section{RESULTADOS E DISCUSSÃO}

O efluente obtido a partir do tratamento das águas residuais da produção de biodiesel via eletrofloculação é composto predominantemente de cloreto ferroso $\left(\mathrm{FeCl}_{2}\right)$, como resultado da eletrólise do cloreto de potássio e do ferro disperso no efluente. O líquido apresentou uma coloração esverdeada, característica da presença do cloreto ferroso (Figura 1). Geralmente, são utilizados dois métodos clássicos para a oxidação de íons $\mathrm{Fe}^{2+}$ em $\mathrm{Fe}^{3+}$ : o primeiro consiste em expor cloreto ferroso ao ar atmosférico, deixando o recipiente aberto. Segundo Silveira et al. (2013, p.4), esse método é ineficaz, pois as velocidades de reação são extremamente baixas e produzem altas concentrações de ferrugem; No segundo método, que foi utilizado no presente trabalho, a adição do ácido clorídrico elimina a presença de ferrugem, o que torna o processo mais eficiente.

O ácido clorídrico elimina a ferrugem devido ao ataque do referido ácido (Equação 1), além de diminuir o pH da solução. $\mathrm{O} \mathrm{HCl}$ foi adicionado até que o $\mathrm{pH}$ da solução estivesse em $1,0 . \mathrm{Em}$ seguida, adicionou-se o peróxido de hidrogênio, que oxidou com maior eficiência os íons $\mathrm{Fe}^{2+}$ em $\mathrm{Fe}^{3+}$ (Equação 2), havendo mudança na coloração da solução que passou de esverdeado (cor característica da presença de íons $\mathrm{Fe}^{2+}$ ) para uma coloração avermelhada (característica da presença de $\mathrm{Fe}^{3+}$ ), em apenas 2 min, o conteúdo de $0,5 \mathrm{~L}$ aparentava a presença predominante da referida coloração avermelhada que é um indicativo que a solução foi convertida em percloreto de ferro. $\mathrm{O}$ sistema foi deixado em repouso por $5 \mathrm{~h}$, conforme descrito anteriormente.

Verificou-se a precipitação do cloreto de ferro formado e uma solução sobrenadante de cloreto de ferro não concentrada. Esta foi retirada com o auxílio de uma pipeta graduada. A solução pode ser utilizada, posteriormente, para ensaios de coagulação de efluentes com sólidos em suspensão e, também, em sistemas de tratamento de água ou esgoto industrial (BARBOSA et 
al., 2014, p. 61). A solução que precipitou foi levada à estufa a $90^{\circ} \mathrm{C}$, por $6 \mathrm{~h}$, para evaporação da água excedente, visando à concentração da solução de percloreto de ferro.

$$
\begin{aligned}
& \mathrm{Fe}(\mathrm{OH})_{3(a q)}+\mathrm{HCl}_{(a q)} \Rightarrow \mathrm{FeCl}_{3(a q)}+3 \mathrm{H}_{2} \mathrm{O}_{(l)} \\
& 2 \mathrm{FeCl}_{2(a q)}+2 \mathrm{HCl}_{(a q)}+\mathrm{H}_{2} \mathrm{O}_{2(l)} \Rightarrow 2 \mathrm{FeCl}_{3(a q)}+2 \mathrm{H}_{2} \mathrm{O}_{(l)}
\end{aligned}
$$

A Figura 2a mostra a placa de circuito impresso após a aplicação da camada de tinta e desenho do circuito, onde a solução de percloreto de ferro irá atuar como agente corrosivo. A Figura $2 \mathrm{~b}$ mostra a placa submersa na solução, o componente ficou exposto ao tratamento durante 5 min sob agitação.

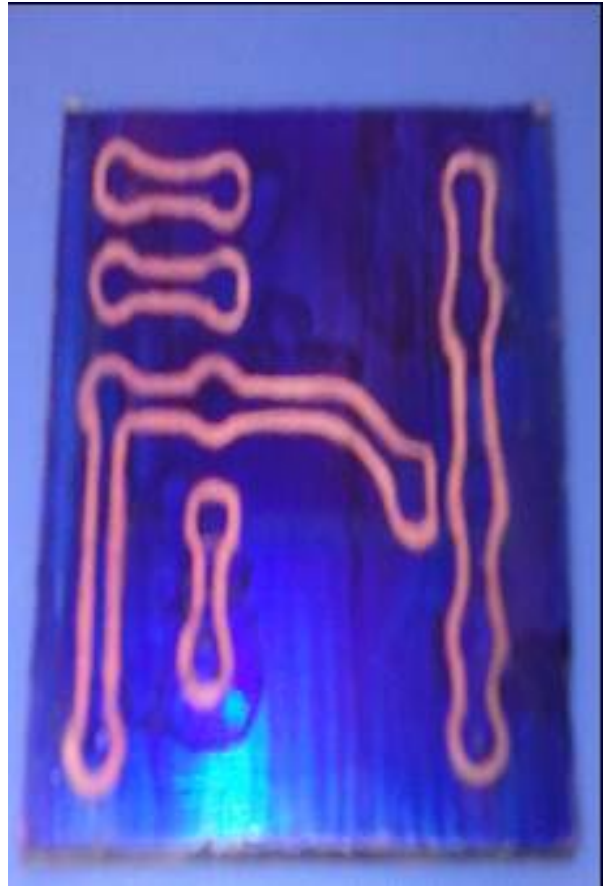

a)

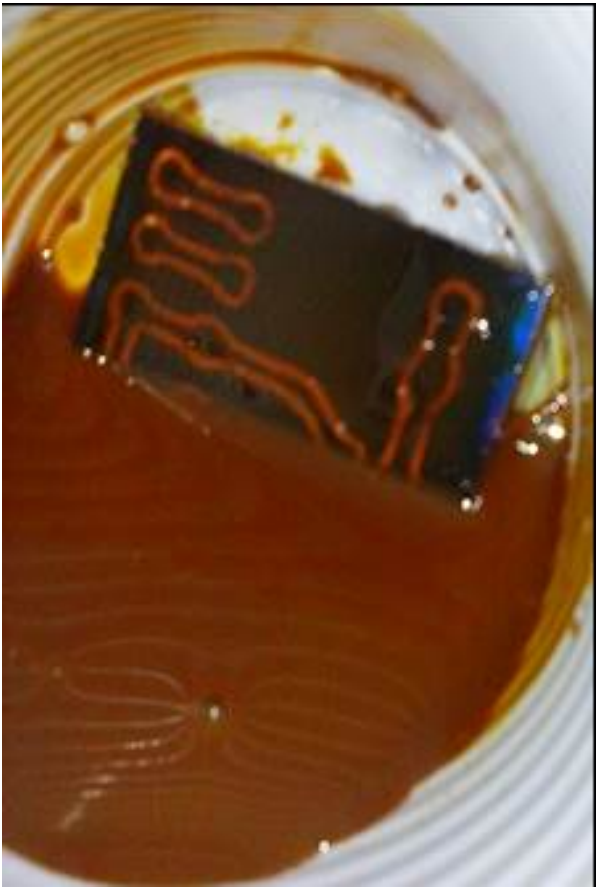

b)

Figura 2: (a) Placa de circuito impresso após aplicação da camada de tinta; (b) Placa submersa na solução de percloreto de ferro

A solução de percloreto de ferro produzida a partir do efluente das águas residuais da produção de biodiesel, tratadas pela técnica de eletrofloculação, mostrou-se eficiente atuando como agente corrosivo em placas de circuito impresso (Figura 3a).

O circuito da Figura $3 b$ corresponde a um retificador de onda completa com derivação central (ou ponto neutro), tal circuito é empregado na conversão de um sinal periódico senoidal com frequência fixa de $60 \mathrm{~Hz}$ fornecida pela rede elétrica. Normalmente, o dispositivo em questão é utilizado na alimentação de aparelhos eletrônicos que necessitam de tensão contínua para funcionar, porém são alimentados em tomadas da rede elétrica de tensão alternada. Geralmente, é localizado na saída do transformador abaixador de tensão, realizando a conversão em tensão 
padrão para circuitos eletrônicos de corrente contínua. As trilhas de cobre delimitadas no restante da placa pela ação do agente corrosivo são destinadas à condução das correntes elétricas, necessária ao funcionamento do circuito, estas devem possuir, basicamente, espessura suficiente para suportar a intensidade do fluxo elétrico.

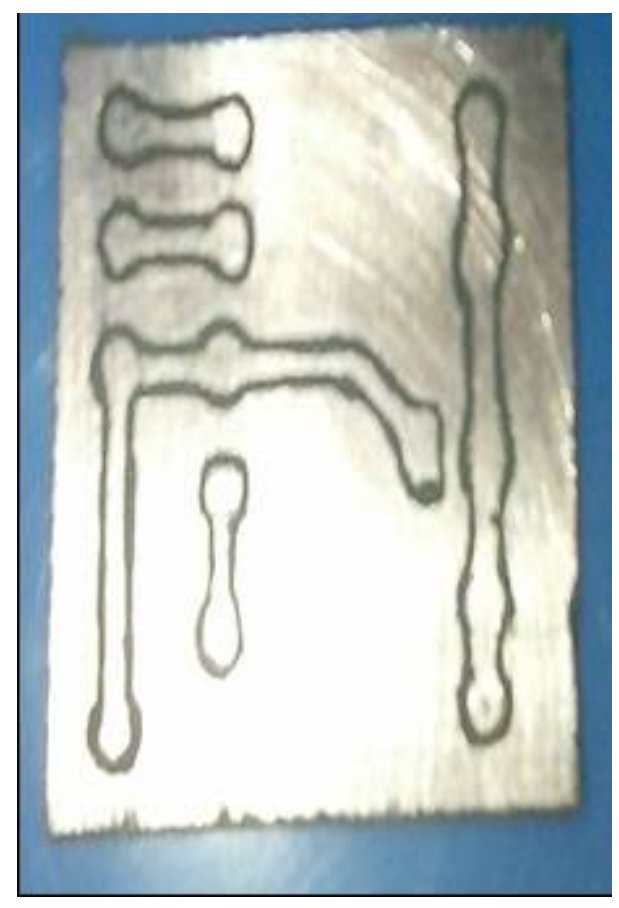

a)

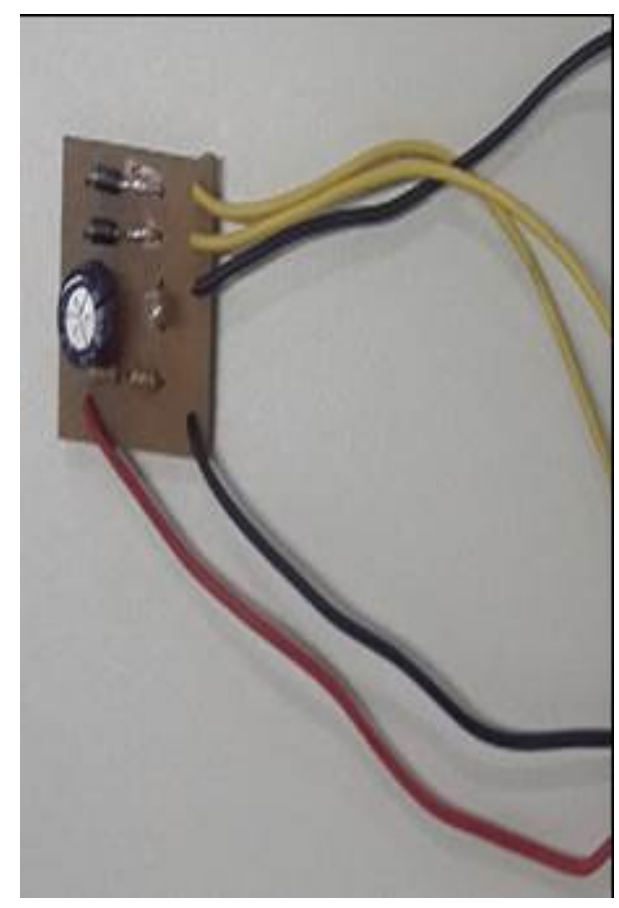

b)

Figura 3: (a) Placa de circuito impresso após a corrosão; (b) Circuito final montado

\section{CONCLUSÃO}

Os resultados obtidos mostraram a possibilidade de síntese do percloreto de ferro, a partir das águas residuais da produção de biodiesel tratadas com a técnica de eletrofloculação. Constatou-se que há duas possibilidades de utilização, a primeira a solução de cloreto de ferro sobrenadante pode ser aplicada amplamente em processos de coagulação/decantação de águas, que contenham sólidos dispersos, bem como, aplicada em tratamento de esgotos industriais. A segunda aplicação, refere-se ao uso do percloreto de ferro como agente corrosivo para confecção de placas de circuito impresso, pode-se afirmar que para este fim o percloreto produzido atendeu satisfatoriamente os objetivos previstos no presente trabalho.

\section{AGRADECIMENTOS}

A FAPESB por conceder bolsa de iniciação científica. 


\section{REFERÊNCIAS}

Barbosa, L., Fernandes, R. C.\& Miyazawa, C. S. (2014). Análise da influência do cloreto de ferro III em ambiente aquático. Revista Scientia Vitae, 1 (4), 61-65.

BRASIL. Resolução CONAMA no 430, 2011. Recuperado de http://www.mma.gov.br/port/conama/legiabre.cfm?codlegi=646.

Cavalcanti, L. A. P. (2013). Reologia e melhoramento das propriedades de escoamento a frio de biodiesel e suas misturas BX. (Tese de Doutorado, Universidade Federal de Pernambuco). Recuperado http://repositorio.ufpe.br/bitstream/handle/123456789/10548/TESE\%20Luiz\%20Antonio\%20Pim entel\%20Cavalcanti.pdf.

Cordeiro, R. B., Alexandre, J. I. S., Silva, J. P. F., Sales, D. C. S. \& Cavalcanti, L. A. P. (2015). Purificação e reutilização de águas residuárias da produção de biodiesel por meio da eletrofloculação. Revista Brasileira de Gestão Ambiental e Sustentabilidade, 2 (2), 51-58. Recuperado de http://revista.ecogestaobrasil.net/v2n2/v02n02a05.html.

Dogan, T. H. \& Temur, H. (2013). Effect of fractional winterization of beef tallow biodiesel on the cold flow properties and viscosity. Fuel, 108, 793-796. doi: 10.1016/j.fuel.2013.02.028

Elicker, C., Flores, C. P., Santos, M. A. Z., Colepicolo, P. \& Pereira, C. M. P. (2015). Estudo da utilização da biomassa de cianobactérias como matéria-prima para a síntese de biodiesel através da reação de esterificação in situ. Revista Virtual de Química, 7 (6), 2497-2508. doi: 10.5935/19846835.20150149

Fleck, L. (2011). Aplicação do controle estatístico de processos ao tratamento de um efluente têxtil por eletrofloculação. (Trabalho de Conclusão de Curso, Universidade Tecnológica Federal do Paraná, Curitiba).

Recuperado de http://repositorio.roca.utfpr.edu.br/jspui/bitstream/1/472/1/MD_COGEA_2011_2_17.pdf. Junqueira, C. N., Franco, M. M., Ruggiero, R., Borges Neto, W., Bueno, J. A. \& Santos, D. Q. (2015). Contaminantes metálicos no biodiesel de soja. Anais do $10^{\circ}$ Congresso Internacional de Bioenergia, São Paulo, 1-8. Recuperado de https://repositorio.ufu.br/handle/123456789/12382

Knothe, G., Gerpen, J. V., Krani, J. \& Ramos, L. P.(2006). Manual do biodiesel. São Paulo: Edgard Blücher.

Moser, B. (2014). Impact of fatty ester composition on low temperature properties of biodieselpetroleum diesel blends. Fuel, 115, 500-506. doi: 10.1016/j.fuel.2013.07.075

Nascimento, F. A., Vieira, S. A., Andrade Júnior, S. J. \& CAVALCANTI, L. A. P.(2015) . Integração de um sistema fotovoltaico isolado e de coleta seletiva de resíduos em um quiosque multifuncional. Revista Brasileira de Gestão Ambiental e Sustentabilidade, 2 (2), 43-50. Recuperado de http://revista.ecogestaobrasil.net/v2n2/v02n02a04.html.

Silveira, R. L.; Dias, T. A.; Rodrigues, T. V.; Belo, E. M. \& Barbosa, H. C. S. (2013). Reciclagem do percloreto de ferro. Anais do XLI Congresso Brasileiro de Educação em Engenharia, COBENGE, 1-8. Recuperado http://www.handmades.com.br/forum/index.php?PHPSESSID=2bll7ev9b4gqmnqu574j4sd062\&topic= 1192.0. 
Vieira, S. P., Nascimento, F. A., Braz, M. A., Andrade Júnior, S. J. \& CAVALCANTI, L. A. P. (2015). Reuso de latinhas de alumínio recicláveis para tratamento de águas residuais da produção de biodiesel via eletrofloculação. Revista Brasileira de Gestão Ambiental e Sustentabilidade, 2 (3), 145-151. Recuperado de http://revista.ecogestaobrasil.net/v2n3/v02n03a07.html. 